Chronic Obstructive Pulmonary Diseases:

Journal of the COPD Foundation

\author{
Letter to the Editor
}

\title{
Nebulized Treatments and the Possible Risk of Coronavirus Transmission: Where is the Evidence?
}

\author{
Donald P. Tashkin, $\mathrm{MD}^{1}$ Igor Z. Barjaktarevic, $\mathrm{MD}, \mathrm{PhD}^{1}$
}

\begin{abstract}
Abbreviations: severe acute respiratory syndrome coronavirus 2, SARS-CoV-2; coronavirus disease 2019, COVID-19; metered-dose inhalers, MDIs; severe acute respiratory syndrome, SARS; health care personnel, HCP; personal protective equipment, PPE; Centers for Disease Control and Prevention, CDC

Date of Acceptance: May 8, 2020

Citation: Tashkin DP, Barjaktarevic IZ. Nebulized treatments and the possible risk of coronoavirus transmission: where is the evidence? Chronic Obstr Pulm Dis. 2020;7(3):136-138. doi: https://doi.org/10.15326/jcopdf.7.3.2020.0161
\end{abstract}

1 David Geffen School of Medicine, University of California, Los Angeles

\section{Address correspondence to:}

Donald P. Tashkin, MD

Email: dtashkin@mednet.ucla.edu

\section{Keywords:}

nebulized treatments; severe acute respiratory syndrome coronavirus 2; SARS-CoV-2; coronavirus disease 2019; COVID-19

\section{Dear Editor:}

The worldwide outbreak of severe acute respiratory syndrome coronavirus 2 (SARS-CoV-2) has brought into focus the need for clear and accurate guidance on the use of aerosol-generating procedures, such as nebulization, for the treatment of patients with respiratory diseases. Of primary concern is the potential risk of release and spread of SARS-CoV-2 in the form of aerosolized respiratory droplets during nebulized treatment of patients with coronavirus disease 2019 (COVID-19). Under controlled environmental conditions, SARS-CoV-2 was shown to be viable in aerosols for up to 3 hours. ${ }^{1}$ A subsequent study by Liu et $\mathrm{al}^{2}$ of aerosolized SARS-CoV-2 RNA in 2 Wuhan hospitals during the COVID-19 outbreak found that room ventilation, open space, sanitization of protective apparel, and disinfection of toilet areas effectively reduced the levels of SARS-CoV-2 RNA in aerosols. However, to err on the side of caution, patients with COVID-19 and respiratory disease are being switched to hand-held devices, such as metered-dose inhalers (MDIs), for the delivery of their medications. Thus, the use of MDIs has risen sharply as an alternative to nebulized therapy, resulting in severe shortages of MDIs. ${ }^{3}$ This abrupt switch also results in some patients having the inability to properly use the new device or receive the full benefits of inhaler therapy because of inadequate hand-mouth coordination, poor inspiratory strength, or other impediments to the use of hand-held devices.

At present, there is significant concern regarding the high transmissibility of SARS-CoV-2. Nevertheless, an assessment of the available data about the risks of nebulizer treatment during an epidemic of respiratory viruses reveals very limited information. In specific relation to the 2002-2003 SARS-CoV outbreaks, a study in a patient with SARS undergoing treatment with a large-volume nebulizer found no evidence of SARS-CoV-specific nucleic acid material in air samples taken from the vicinity, $30 \mathrm{~cm}$ above the patient's head. ${ }^{4}$ A 2012 assessment of 3 cohort studies found no statistically significant risk of SARS-CoV transmission to health care personnel (HCP) caring for patients undergoing nebulizer treatment. ${ }^{5}$ In the 2019-2020 SARS-CoV-2 pandemic, the first U.S. case of community-acquired COVID-19 was confirmed on February 26, 2020 in a patient hospitalized in Solano County, California. Of note, COVID-19 was not suspected, and none of the HCP wore personal protective equipment (PPE) at the time of patient admission. The patient underwent multiple aerosol- 
generating procedures, including nebulization. A recent report of that incident by the Centers for Disease Control and Prevention (CDC) ${ }^{6}$ found that $121 \mathrm{HCP}$ were exposed to this patient. Forty-three developed symptoms and were tested for SARS-CoV-2; of these, 3 had positive test results. All $3 \mathrm{HCP}$ had unprotected contact with the patient, thus making it difficult to determine the degree of involvement of nebulization on SARS-CoV-2 transmission in this instance.

As per the CDC, there are no currently known links between performing nebulized treatments and an increased risk of SARS-CoV-2 infection. ${ }^{7}$ Although it is difficult to ascertain whether the possible risk of transmission is directly related to the use of a nebulizer or increased contact between the infected person and the HCP administering the treatment, ${ }^{7}$ the $\mathrm{CDC}$ recommends early recognition and isolation of patients with possible infection and the use of PPE by HCP. ${ }^{6}$ The Minnesota Department of Health mostly mirrors the CDC guidelines, but further recommends the use of nebulizers for those patients who need it, or switch to MDIs for those who can tolerate it. ${ }^{8}$ The National Institute for Health and Care Excellence ${ }^{9}$ and the UK government guidance from the New and Emerging Respiratory Virus Threats Advisory Group $^{10}$ advise the continued use of nebulizers because administration of medication via nebulization is not considered to represent a significant infectious risk. This is because the aerosol produced during nebulizer treatment is not patient-derived but is generated from fluid from the nebulizer chamber, and therefore, does not carry patient-derived viral particles. If a particle in the aerosol comes into contact with a patient's contaminated mucous membrane, it will cease to be airborne and therefore, will not be part of an aerosol. The guidance further notes that HCP should use appropriate hand hygiene when helping patients remove nebulizers and oxygen masks. The COPD Foundation offers additional guidance to use a filter (equivalent to an N95 mask) with nebulizers to filter the patient's exhaled air, and thus limit the risk of virus spread. ${ }^{11}$

The following should be considered based on the current guidance and limited evidence of increased infection risk with nebulized therapy. From the perspective of an uninfected patient at home, there are no known infection-related hazards that preclude the use of a nebulizer. The use of nebulized treatment by a patient with COVID-19 at home has no known hazards to that patient. If this patient is following social distancing guidelines and undertaking extra precautions such as increased nebulizer hygiene, avoidance of nebulizer use in the presence of other people, and ensuring that the nebulizer treatment is done near open windows or in areas of increased air circulation, the risks toward other people can be minimized as well. From the perspective of public health, hospitals and health care facilities should continue to adhere to strict measures that protect $\mathrm{HCP}$ from SARS-CoV-2 infection, including adherence to stringent sanitization protocols and use of PPE in the presence of COVID-19 patients. In the case of a patient undergoing nebulized treatment, the use of negativepressure rooms, disposing of used equipment after each use, and maintaining at least 6 feet or greater distance from the patient should be considered.

Altogether, given the absence of any conclusive data showing that nebulizer treatments promote the dispersal of coronavirus particles, institutional guidance and physicians should adjust to their practice setting and base their decisions on current information. As we obtain new data, they should consider modifying their prescription of either handheld devices or nebulizers accordingly for delivery of needed bronchodilator therapy in hospitalized patients with COVID-19. In addition, proper precautions should be used as per the current guidance consensus to prevent the spread of SARS-CoV-2.

\section{Acknowledgments}

Medical writing support was funded by Theravance Biopharma US, Inc. (South San Francisco, California). The authors acknowledge Gautam Bijur, PhD, for medical writing and Frederique H. Evans, MBS, for editorial assistance (both from Ashfield Healthcare Communications) in the preparation of the document.

\section{Declaration of Interest}

DPT has served as a consultant and speaker for AstraZeneca, Boehringer Ingelheim, Sunovion, and Mylan/Theravance Biopharma, Inc., and as a consultant for GlaxoSmithKline. IZB has consulted with AstraZeneca, Boehringer Ingelheim, CSL Behring, Grifols, Verona Pharma, GE Healthcare, Mylan, Theravance Biopharma, Inc., and GlaxoSmithKline and has received research grants from AMGEN, Theravance, Mylan and GE Healthcare. 


\section{References}

1. van Doremalen N, Morris DH, Holbrook MG, et al. Aerosol and surface stability of SARS-CoV-2 as compared with SARS-CoV-1. N Engl J Med. 2020;382(16):1564-1567. doi: https://doi.org/10.1056/NEJMc2004973

2. Liu Y, Ning Z, Chen Y, et al. Aerodynamic analysis of SARSCoV-2 in two Wuhan hospitals. Nature. 2020; In press. Accessed April 30, 2020. doi: https://doi.org/10.1038/s41586-020-2271-3

3. American College of Allergy, Asthma \& Immunology. A message to asthma sufferers about a shortage of albuterol metered dose inhalers. 2020. Published April 9, 2020. Accessed April 30, 2020. https://acaai.org/news/message-asthma-sufferers-aboutshortage-albuterol-metered-dose-inhalers

4. Wan GH, Tsai YH, Wu YK, Tsao KC. A large-volume nebulizer would not be an infectious source for severe acute respiratory syndrome. Infect Control Hosp Epidemiol. 2004;25(12):11131115. doi: https://doi.org/10.1086/502353

5. Tran K, Cimon K, Severn M, Pessoa-Silva CL, Conly J. Aerosol generating procedures and risk of transmission of acute respiratory infections to healthcare workers: a systematic review. PLoS One. 2012;7(4):e35797.

doi: https://doi.org/10.1371/journal.pone.0035797

6. Heinzerling A, Stuckey MJ, Scheur T, et al. Transmission of COVID-19 to health care personnel during exposures to a hospitalized patient - Solano County, California, February 2020. MMWR Morb Mortal Wkly Rep. 2020;69(15):472-476.

doi: https://doi.org/10.15585/mmwr.mm6915e5

7. Centers for Disease Control and Prevention. Coronavirus disease 2019 (COVID-19) Healthcare infection prevention and control FAQs for COVID-19. Updated April 23, 2020. Accessed April 30, 2020. https://www.cdc.gov/coronavirus/2019-ncov/ hcp/infection-control-faq.html

8. Minnesota Department of Health. Aerosol-generating procedures and patients with suspected or confirmed COVID-19. Accessed April 30, 2020. https://www.health.state. mn.us/diseases/coronavirus/hcp/aerosol.pdf

9. National Institute for Health and Care Excellence. COVID-19 rapid guideline: community-based care of patients with chronic obstructive pulmonary disease (COPD). Published April 9, 2020. Accessed April 30, 2020. https://www.nice.org.uk/guidance/ ng 168/resources/covid19-rapid-guideline-communitybasedcare-of-patients-with-chronic-obstructive-pulmonary-diseasecopd-pdf-66141907467973

10. United Kingdom Government. New and Emerging Respiratory Virus Threats Advisory Group (NERVTAG). Accessed April 30, 2020. https://www.gov.uk/government/publications/wuhannovel-coronavirus-infection-prevention-and-control/covid-19personal-protective-equipment-ppe 